\title{
2.
}

-T.

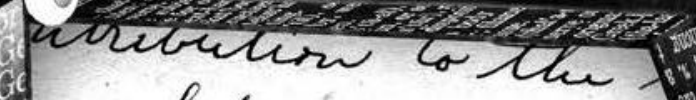

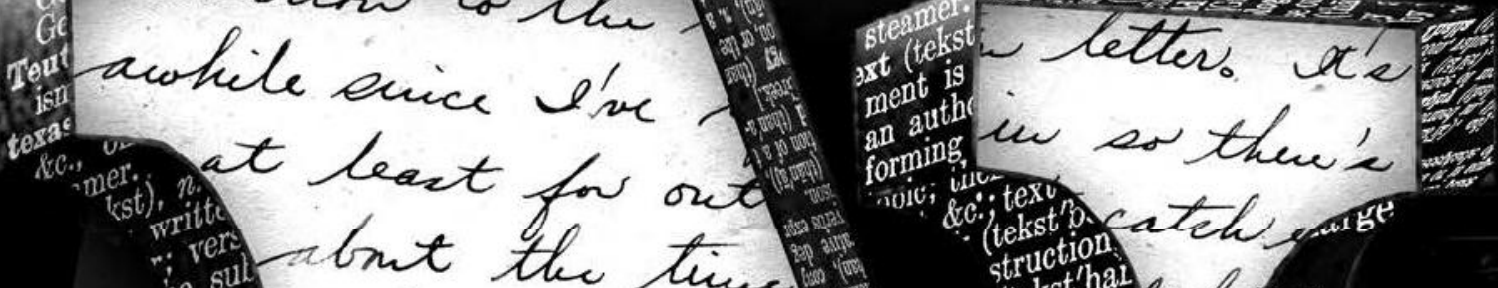
"iver sul abut the tive is

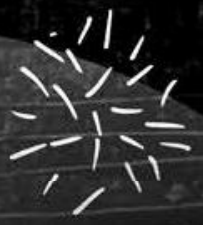<smiles>[CH]</smiles>

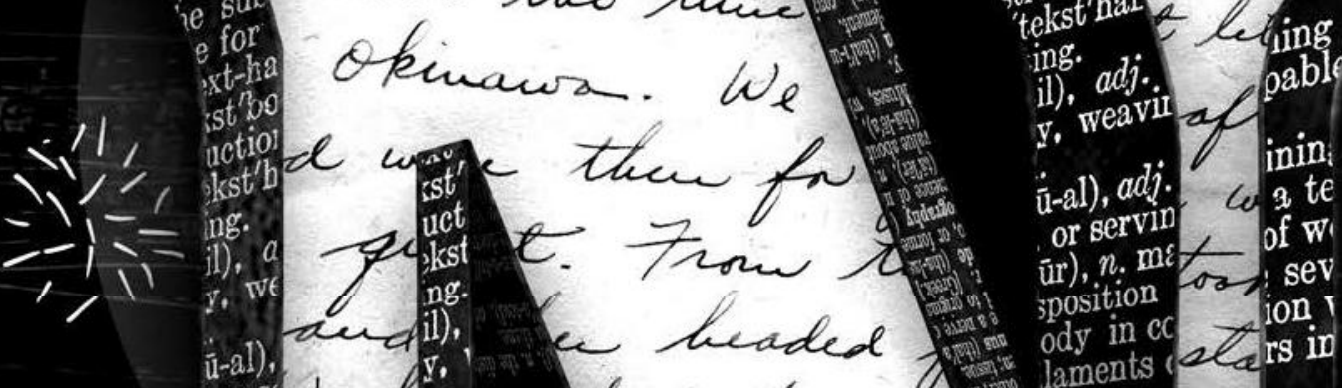

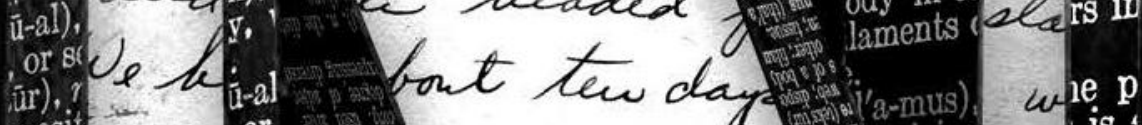

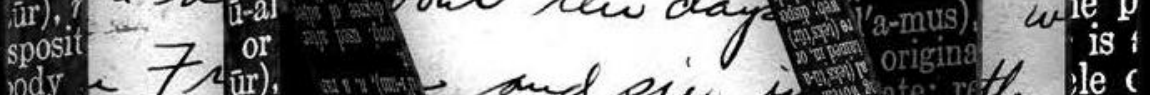

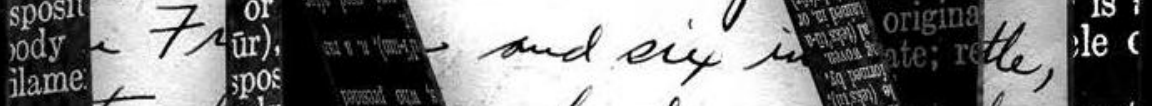

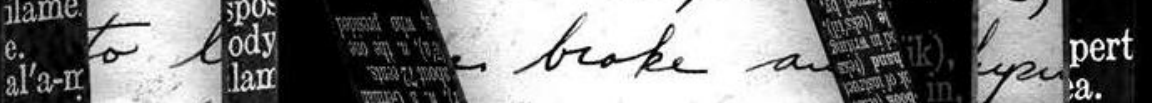

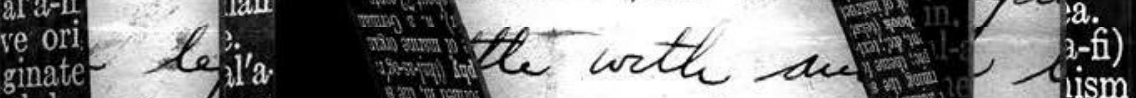

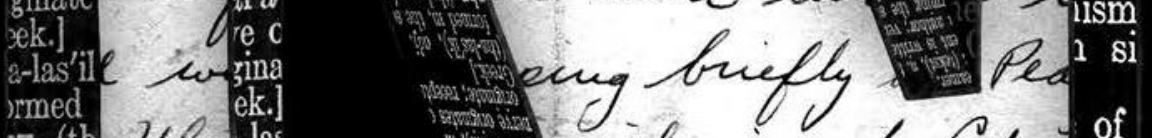
rmed ek.] iv (th 2Clatas of mas me bout 7 these 7 in $\left.j^{\prime} a\right), n$.

3, whoter giout औ'i-um says wi degrecung is cong $\left.i^{\prime} a \bar{j}\right)$, wadeg epiderme of Cat ${ }_{d}$ of , ing then wasn't evenare. (x) in

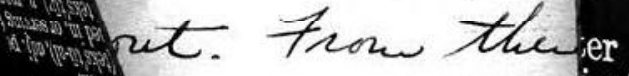

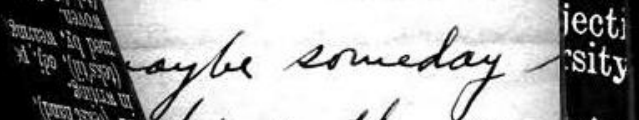
"vind the waringt

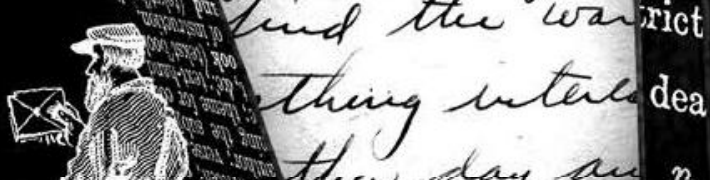

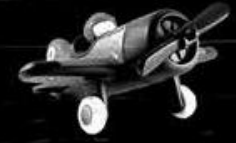

of aly, Son then day ann.

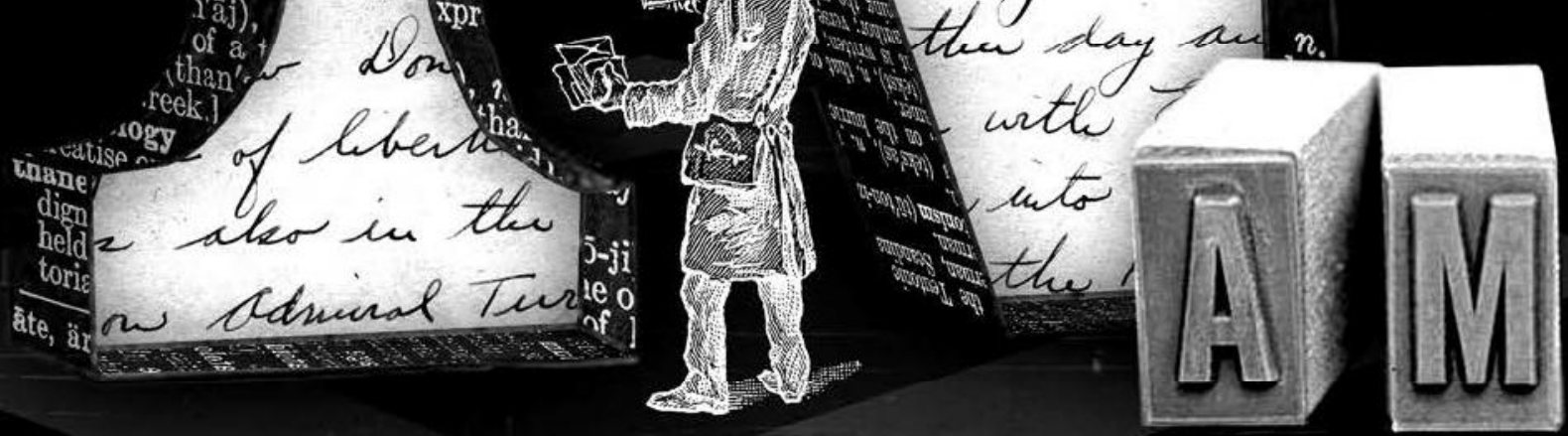




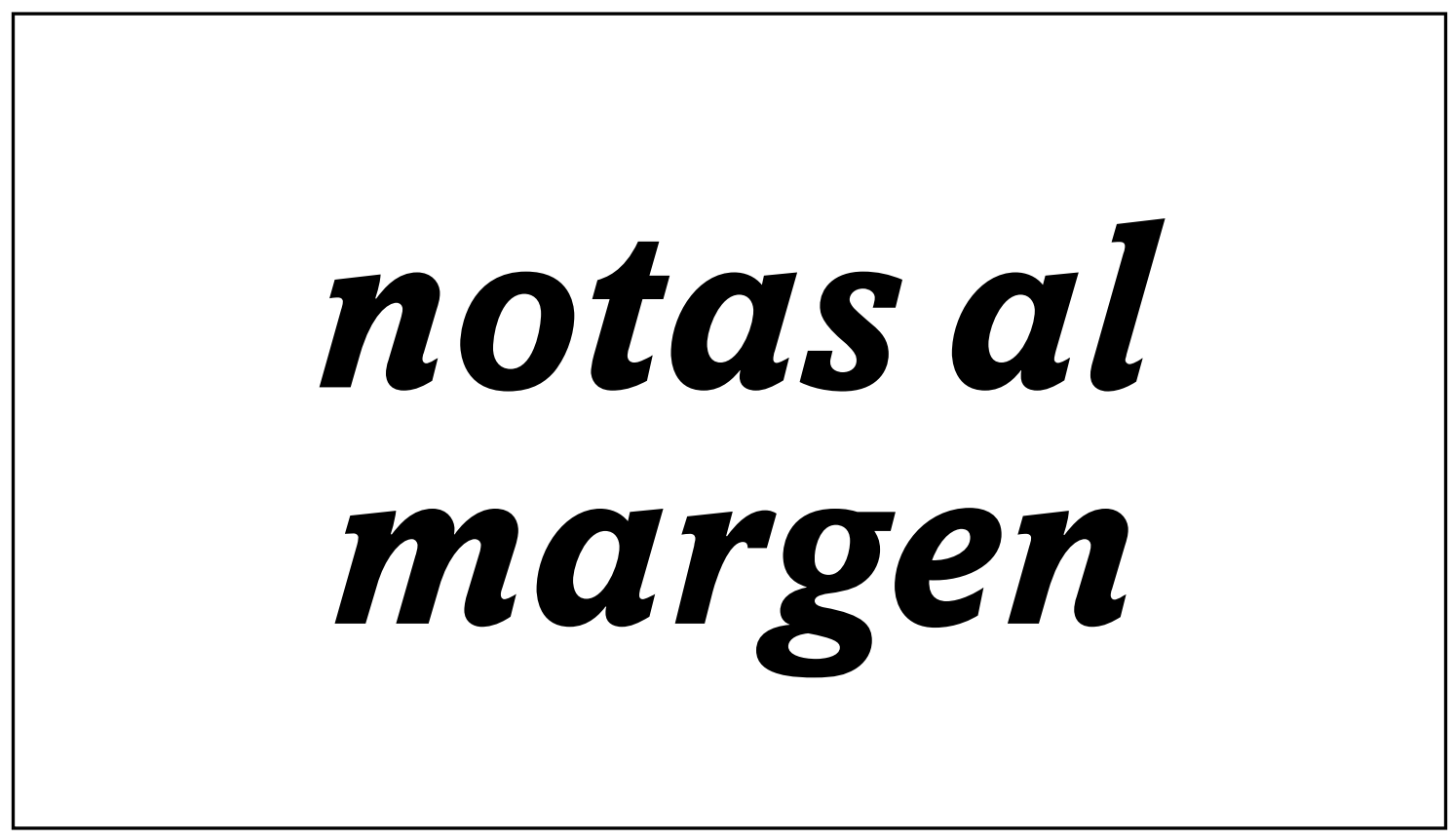




\section{¡Peligro! La defensoría pública defiende a las víctimas del conflicto armado}

Danger! The public defender defends the victims of armed conflict

¡Perigo! A defensoría pública defende às vítimas do conflito armado

\section{Luis Alejandro Lemus González}

alejo5966@gmail.com

Universidad Pedagógica y Tecnológica de Colombia

Estudiante Maestría en Derechos Humanos

Artículo recibido: 20/05/2016 - Artículo aprobado: 27/06/2016

Para citar este artículo: Lemus, L.A. (2016). ¡Peligro! La defensoria pública

defiende a las víctimas del conflicto armado. Ciudad paz-ando, 9(1),

pp. $139-149$ 


\section{RESUMEN}

Este artículo resultado de investigación, contribuye al diagnóstico y pronóstico de un problema jurídico y social, cuya solución también propongo en el cuerpo del mismo. El artículo llega a la conclusión de cómo a las víctimas del conflicto armado colombiano, no se les ha representado en debida forma por parte de la Defensoría del Pueblo, y a consecuencia de ello, no han recibido integrales indemnizaciones patrimoniales e individuales de conformidad con la teoría del daño y su prueba. Como solución, se propone que los defensores y defensoras de oficio sigan un sencillo protocolo cuando estén argumentando los incidentes de reparación integral, ya que si lo hacen, también se beneficiarían las víctimas que sean reconocidas en el marco de la futura jurisdicción especial para la paz.

Palabras clave: defensa judicial, reparación individual plena, política pública, revictimización.

This article is the result of a completed investigation; it contributes to the diagnosis and prognosis of a legal and social problem whose solution also propose the switch body. The article comes to the proposal that our victims of the Colombian armed conflict conclusion, not represented them properly by the Ombudsman, as a result, have not received comprehensive economic and individual compensation in accordance with the theory of damage and testing. As a solution, I urge defenders office to follow a simple protocol when they are arguing incidents of reparation, because if they do, also victims who are recognized as part of the future special jurisdiction to benefit the peace.

Keywords: Judicial Defense, full individual reparation, public policy, revictimization.
Este artigo que é o resultado de uma investigação terminada, contribui ao diagnóstico e prognóstico de um problema jurídico e social, cuja solução também proponho no corpo do mesmo. O artigo chega à conclusão consistente em que, a nossas vítimas do conflito armado colombiano, não se lhes tem representado em devida forma por parte da defensoría, e em consequência disso não têm recebido integrais indemnizações patrimoniais e individuais de conformidade com a teoria do dano e sua prova. Como solução, insto aos defensores e defensoras de oficio para que sigam um singelo protocolo quando estejam a argumentar os incidentes de reparo integral, já que se o fazem, também beneficiar-se-iam as vítimas que sejam reconhecidas no marco da futura jurisdição especial para a paz.

Palavras-chave: defesa judicial, reparo individual plena, política pública, revictimización. 


\section{Introducción}

$\mathrm{E}$ l presente artículo es el resultado crítico reflexivo de una investigación realizada para la Universidad Pedagógica y tecnológica de Colombia [UPTC], y que el suscrito postulado a magister empezó a perfeccionar en el mes de abril del año inmediatamente anterior, es decir, en el 2015, y la cual recibió sus últimas pinceladas y la respectiva aprobación, en el mes de septiembre del presente año 2016.

Como abogado litigante, una de las líneas en las que me desenvuelvo, es la relacionada con la defensa de víctimas del paramilitarismo al interior de los tribunales de justicia y paz, y fue precisamente la experiencia que viví en el tribunal de justicia y paz de Bogotá, lo que me llevó a desarrollar la investigación que presenté como trabajo de grado ante la UPTC, y de la cual deviene este artículo. Los motivos que me llevaron a escribir sobre las víctimas del conflicto armado paramilitar, y sobre la forma como vienen siendo revictimizadas al interior del foro judicial de justicia y paz, y sobre por qué proyectivamente estoy seguro que también serán revictimizadas las que sean reconocidas después de la coyuntura habanera. Esos motivos los encontramos en el fenómeno de revictimización originado en las bajísimas y risibles indemnizaciones económicas e individuales que viene otorgando la honorable magistratura a quo.

Bajas reparaciones que además son confirmadas cuando no disminuidas, en sede de alzada, por parte de la Honorable Corte Suprema de Justicia como una revictimización que encuentra su génesis en últimas, en la pésima labor defensorial que viene siendo desplegada por parte del sistema nacional de defensoría pública en cabeza de sus órganos o agentes. De modo que lo que sostengo en este artículo, es que los defensores y defensoras de oficio que han estado y que actualmente se encuentran destacados ante justicia y paz, son los directamente responsables de esas bajas reparaciones monetarias que se les reconoce a nuestras víctimas, a causa por supuesto, de su desconocimiento de los elementos teóricos del daño, y debido a su negligencia en el debate probatorio, y a su desinterés y mala fe para con las víctimas que entrecomillas representan.

El tráfico jurídico social comporta para las personas el peligro constante de llegar a ser dañadas, es por ello que el daño o perjuicio es una contingencia inherente al ser humano que puede afectar la esfera anímica, o el patrimonio económico, y por ello es que debe ser reparado o indemnizado. De Cupis (1970) afirma. "Mal podría suponerse entonces una sociedad que tuviera por principio la no reparación del daño sufrido, pues ello implicaría la ruptura del orden social, y la aceptación de la posibilidad ilimitada de causar daño" (p.82).

Por supuesto que en nuestro contexto de conflicto armado paramilitar y de confrontación Estado - guerrilla. "Nuestra sociedad no desea preservar la vida humana a toda costa en su sentido más amplio, la idea desagradable de que estamos dispuestos a destruir la vida nos ha de resultar evidente. Existe la guerra” (Calabresi, 1984, p.35).

Lo anterior significa que el norte ético y político en torno al cual gira este artículo de reflexión crítica, lo constituye la indemnización individual, integral y dineraria de las víctimas del conflicto armado colombiano, ya que dentro de las múltiples opciones que tienen las sociedades para hacer frente a sus daños y perjuicios, interesa a este articulista, la opción que se desarrolla a través del litigio de responsabilidad civil al interior del incidente de reparación integral en justicia y paz, así como la opción que se destilará procesalmente a partir de febrero o marzo del año 2017 al interior de la jurisdicción especial para la paz [JEP].

Como anticipación de las conclusiones, puedo afirmar desde ya, puesto que así se evidenciará en los resultados de este artículo reflexivo en clave crítica, que del estudio, muestreo o análisis de las 27 sentencias que para el mes de julio del año 2016 habían sido emitidas por el tribunal de justicia y paz de Bogotá, se desprende la desidia de nuestros defensores y defensoras públicos/as, quienes no defienden adecuadamente para que las víctimas lleguen a ser indemnizadas de conformidad con la teoría del daño y su prueba.

De hecho veremos un corto análisis de algunas de las 27 sentencias que en su momento investigué, en donde se muestra cómo en las más de 20 sentencias que se profirieron hasta el mes de julio del año 2016 en las salas de audiencias del tribunal de justicia y paz de la capital de la república, la magistratura fue, es y, seguirá siendo incisiva en sus llamados de atención y en las críticas a los defensores/as públicos/as, a raíz de las pésimas defensas adelantadas, ya que en todos estos precedentes jurisprudenciales, se increpó a estos abogados y abogadas diciéndoles que en la mayoría de los casos no probaron los perjuicios como lo tenían que hacer, o que se limitaron a pedir, pero que no respaldaron las solicitudes indemnizatorias con pruebas 
testimoniales o documentales que, es con las que se acredita por ejemplo el parentesco, pues se limitaron a presentar declaraciones extrajuicio, o a invocar principios como la buena fe o la flexibilización probatoria, o a atenerse a las presunciones pretorianas o de hombre, pero sin allegar elementos de prueba idóneos y sencillos de arrimar.

De acuerdo con lo expuesto, un resultado importante de este artículo, será el de indagar si la intención de indemnizar integralmente a las víctimas, ab initio plasmada en los preceptos $8^{\circ}$, y 44 a 49 de la ley 975 del año 2005 , respecto del componente dinerario de reparación, ha sido acogida en sus sentencias por parte del tribunal de justicia y paz de Bogotáy, veremos cómo, si esa intención no ha sido del todo asumida y acogida por la magistratura a quo de justicia y paz - Bogotá, se debe a las nefandas asistencias judiciales de la defensoría pública. Este artículo critica en clave de derecho humanos una política pública, habida cuenta itero que, la defensa de las víctimas por parte de la defensoría del pueblo es una política pública, veremos otro resultado que es cómo esa política pública, realmente sí ha obstaculizado la adecuada indemnización económica de las víctimas para-estatales.

\section{Problema de investigación}

El análisis de la problemática que se aborda en este artículo es una cuestión de actualidad. Las víctimas del paramilitarismo aún están vigentes, así como en el inmediato futuro también cobrarán vigencia en el ámbito procesal de la jurisdicción especial para la paz [JEP] las víctimas de la guerrilla, una vez firmado el acuerdo final el 26 de septiembre y, con la posterior aprobación del plebiscito el 02 de octubre del año en curso.

El problema de investigación consiste entonces en la revictimización a causa de la no reparación dineraria e integral, revictimización que encuentra su génesis en las desastrosas asistencias judiciales desplegadas por parte de la defensoría del pueblo, ya que no puede hablarse de plenas reparaciones, cuando por el homicidio en persona protegida y posterior desaparición forzada pero, previo descuartizamiento de su deudo, a las víctimas indirectas se les indemniza con sumas irrisorias, a veces de veinte (20), o de cincuenta (50), o de setenta (70) SMLMV, sólo porque su abogada/o defensor/a no aportó documentos, o porque no tenía poder para representarlas, etcétera.
Y no me estoy refiriendo acá a los topes administrativos de indemnización que fueran instalados por el artículo 149 del decreto reglamentario número 4.800 del año 2011, reglamentario a su vez de la ley 1448 del mismo año, no, me estoy refiriendo es a las sumas de dinero que, sin tomar en consideración esos techos, están siendo otorgadas por nuestras magistradas y magistrados de justicia y paz.

Demostraré cómo en las sentencias y no sólo en la última que fuera fechada el 29 de febrero del año 2016, dictada contra el bloque central de las autodefensas del Magdalena medio, a la mayoría de las víctimas y, por delitos similares en cuanto a su gravedad, se les reconoció sumas demasiado bajas a título de reparación patrimonial, cifras del orden de 20, 50 o 70 SMLMV.

Y obviamente contrastaré cómo las víctimas que el suscrito articulista representó en esa última sentencia, sí se vieron beneficiadas con indemnizaciones superiores a los mil trescientos millones de pesos colombianos $\left(\$ 1.300^{\prime} 000.000\right)$, es decir, se mostrará cómo logré que reconocieran la suma de $\$ 335^{\prime} 455.663$ para cada una de ellas, lo que en mi sentir y sin el ánimo de sonar prepotente, creo que constituye un hito en Colombia en punto de reparaciones individuales y dinerarias en justicia y paz.

\section{Análisis y/o muestreo jurisprudencial tanto en primera como en segunda instancia}

En la primera sentencia proferida por parte del juez colegiado de justicia y paz - Bogotá, los defensores públicos, en lugar de acudir como lo hicieron al fácil expediente de solicitar genérica y uniformemente equis cantidad de salarios mínimos para todas sus víctimas, debieron haber procedido a aportar experticias psiquiátricas, o pedir el decreto y posterior práctica de declaraciones a testigos, para que así la magistratura, no hubiese tenido excusa alguna para denegar el reconocimiento de los daños inmateriales. Por ejemplo, en relación con el daño emergente y el lucro cesante, se limitaron simplemente a elevar sus millonarias peticiones sin ningún tipo de soporte actuarial, es decir, como si se hubieran inventado los cálculos actuariales por lucro cesante y, prueba de esto que estoy afirmando, se lee en la página No 107 de la sentencia que a continuación se reseña, en donde dicen los magistrados que: "se observa que el defensor público de la víctima Nelson Rocha, cuantifica el 
daño emergente, así como el lucro cesante, con un índice de actualización que no se explica".

Esta primera sentencia emanada de un tribunal de justicia y paz a nivel nacional, se dio en Bogotá, mediante providencia del veintinueve de junio del año 2010 [Mampujan], bajo el radicado No 110016000253200680077 , con ponencia de la honorable magistrada Uldi Teresa Jiménez López, y cuyos postulados fueron, Edwar Cobos Téllez, alias "Diego vecino" y, Uber Enrique Banquéz Martínez, alias "Juancho dique". Dentro de este primer contexto jurisprudencial, en principio fueron reconocidas 1.799 víctimas por diferentes conductas punibles, entre homicidios, desplazamientos forzados rurales y urbanos, secuestros, etcétera., es decir, el guarismo anterior es arrojado de la sumatoria de las víctimas de todos los defensores públicos, tal y como se evidencia de las páginas 7 a 32 de la mentada providencia, pero extrañamente, en la parte final de esta sentencia, concretamente en la página 95 del capítulo VIII, atinente al "incidente de reparación integral", la Sala sólo señala finalmente a 1.194 víctimas reconocidas, ¿qué pasó con las otras 605 víctimas que se contabilizaron al principio? ¿también fueron víctimas de desaparición forzada sólo que procesal?

\section{Bajísimas reparaciones y desaparición forzada, sólo que esta vez a nivel procesal}

Al defensor público Miguel Ángel Ramírez Gaitán, quien asumió la defensa masiva de 28 víctimas tal y como se ve a folios 7 a 8 de esta $1^{\text {a }}$ sentencia, solo le conceden unas bajísimas indemnizaciones de $\$ 40^{\prime} 000.000$ por persona para 5 víctimas de uno de los núcleos familiares que representó, y de $12,000.000$ por persona para 10 víctimas de otro núcleo, para un total de $320^{\prime} 000.000$, suma esta que no sólo difiere considerablemente de los $\$ 11.154$ '912.112 que en su momento deprecó sin ningún tipo de soporte actuarial, sino que además, dentro del itinerario procesal de justicia y paz, se le desaparecieron 13 víctimas que inicialmente le habían sido reconocidas.

Al defensor público Humberto Jaimes, quien asumió la defensa de 414 víctimas según páginas 9 a 12, solo le conceden indemnizaciones de $\$ 17^{\prime} 000.000$ por persona para 168 víctimas de uno de los núcleos, y de $13^{\prime} 000.000$ por persona para 9 víctimas de otro núcleo, y de $15^{\prime} 000.000$ por persona para 8 víctimas de otro, para un total de 3.093’000.000, suma esta que está muy alejada de los $\$ 21.282$ ' 445.980 que inicialmente había solicitado sin ningún tipo de soporte actuarial, sino que además, por el camino procesal se le perdieron 229 víctimas.

A la defensora pública Yudi Marinella, quien asumió la defensa de 230 víctimas según se observa a folios 12 a 16 , solo le conceden indemnizaciones de $\$ 10$ '909.000 por persona para 33 víctimas de uno de sus núcleos, y de 17’000.000 por persona para 130 víctimas de otro, y de $10^{\prime} 000.000$ por persona para 13 víctimas de otro, y de $15^{\prime} 000.000$ por persona para 32 víctimas de otro, y de 9'230.000 por persona para 13 víctimas de otro, y de $13^{\prime} 333.000$ por persona para 9 víctimas de otro, para un total de 3.419'984.000, suma esta que también es abismal si se compara con los \$18.692'614.424 que había pedido sin ningún tipo de soporte actuarial y, además, en el trayecto procesal se le desaparecieron 13 víctimas.

Al defensor público Edilberto Carrero, quien asumió la defensa de 168 víctimas como se ve a páginas 19 a 22, solo le conceden indemnizaciones de $\$ 17^{\prime} 000.000$ por persona para 45 víctimas de uno de sus núcleos, y de 13’333.000 por persona para 9 víctimas de otro, y de 7' 500.000 por persona para 16 víctimas de otro, para un total de 1.004'997.000, suma esta que difiere de los $\$ 2.782$ '994.000 que había ab initio deprecado sin soportes actuariales y, en el iter procesal, se le desapareció la bobadita de 98 víctimas.

Y así sucesivamente ocurrió con todos los/las defensores/as públicos/as, a unos se les desaparecieron por el camino más víctimas que a otros...

\section{Crítica a la falacia de los supuestos "millonarios" reconocimientos en las primeras sentencias. Distractores}

Para nada resulta ser cierto, tal y como sagazmente lo quisieron hacer ver algunas personas ante los mass media y la opinión pública, que en las primeras sentencias producidas en los tribunales de justicia y paz, se hayan otorgado en favor de las víctimas, y desde el punto de vista de la reparación dineraria individual, reconocimientos indemnizatorios millonarios. Ocurre que se trató de un distractor que hábilmente fue sembrado en el imaginario colectivo, ese fue el cuento que se le vendió a la ciudadanía, ya que, si se miran las cifras en forma global, parecería que en efecto, 
las primeras víctimas se forraron en dinero, pero si se concretan análisis individuales, como debe ser, la realidad que aflora es la diametralmente opuesta.

Si no me creen, hagamos entonces un rápido sondeo al desplazamiento masivo de San Cayetano, para así probar mi aserto. Resulta que, a las 152 víctimas del desplazamiento de San Cayetano, y que fueran representadas por el defensor público Fernando Rivera, se les reconoció en conjunto, no individualmente, la suma de dos mil cuatrocientos treinta y dos millones de pesos (\$2.432’000.000).

Fíjense cómo a partir de esa cifra global, fue que se procedió a vender ante los medios masivos de comunicación y en general ante la ciudadanía, la mentira consistente en que en estas primeras sentencias, se reconocieron reparaciones cuantiosísimas, ¡nada más alejado de la realidad!, ¡Claro que fueron cuantiosas!, pero como cifras globales, más no individualmente consideradas para cada víctima, pues cada víctima, no fue reparada con el guarismo de $\$ 2.432 ’ 000.000$, si no con la pírrica suma de $\$ 17^{\prime} 000.000$, es decir, de 33 SMLMV de la época, o sea que en la práctica e individualmente consideradas, estas personas recibieron sumas de dinero incluso inferiores a las consagradas en su momento en las disposiciones legales contentivas de los topes administrativos de reparación.

\section{Paliza a nuestras víctimas en segunda instancia, ahora ante la Corte Suprema}

Pero es que la negligencia de la defensoría pública en cabeza de sus defensores de oficio delegados, no se agota ante el juez colegiado a quo, pues el desconocimiento por parte de esos licenciados y licenciadas, respecto de los elementos teóricos del daño, así como de las reglas mínimas del derecho probatorio orientadas a su acreditación, ha hecho que en sede de alzada, esto es, ante la sala de casación penal de la honorable Corte Suprema de Justicia, algunos rubros del daño que ante el juez colegiado de primer grado les habían sido reconocidos, ante el superior funcional y/o en grado de conocimientos, fueron para desgracia de las víctimas, lamentablemente rebajados. La segunda instancia de esta primera sentencia, fue desatada el día 27 de abril del año 2011 por la Corte Suprema, con ponencia de la magistrada María del Rosario González de Lemos, procediendo esta superioridad, a disminuir ostensiblemente los reconocimientos indemnizatorios individuales que habían sido objeto de otorgamiento ante el tribunal, y esto debido a que los defensores públicos no probaron en el incidente de reparación integral, cuestiones elementales de la teoría del daño, en definitiva, miremos el quantum de las rebajas que es lo que más nos interesa:

Al defensor público Miguel Ángel Ramírez Gaitán, de 320’000.000 que le habían reconocido ante el a quo para todas las víctimas que representó, la Corte Suprema le rebajó a 205'000.000. Al defensor público Leonardo Andrés Vega, de 510'000.000 que le habían reconocido en la primera instancia, la corte le bajó a 153'000.000. Al defensor público Alcides Contreras, de 580'000.000 que le habían reconocido, la corte le bajó a 256'000.000. Al defensor público Humberto Jaimes, de 3.093’000.000 para sus centenares de víctimas, la corte le bajó a 3.010'000'000. A la defensora pública Yudi Marinella, de 3.419'984.000 para sus cientos de víctimas, le bajaron a 3.016'000'000.

Al defensor público Julio Enrique Sanabria, de 3.093 '000.000 que le concedieron para sus 172 víctimas representadas, la suprema le bajó a 2.723'000'000. Al defensor público Fernando Olarte, de 1.666'000.000 que le concedieron por los centenares de víctimas que apadrinó, le disminuyeron a 1.615'000'000. Al defensor público Carmelo Vergara Niño, de 2.826'997.000 que le habían concedido por sus cientos de víctimas, le bajaron a $2.623^{\prime} 000^{\prime} 000$.

\section{La deplorable defensa de víctimas en Colombia, tal y como viene siendo ejercida por la defensoría pública, se tipifica como reato de prevaricato por omisión}

El tipo penal consagrado en el artículo 414 de la Ley 599 del año 2000 o código penal vigente, reza que incurrirá en esta conducta delictiva, el servidor público que omita un acto propio de sus funciones, y dice, además, que las consecuencias jurídicas consisten en pena de prisión; imposición de multa, e inhabilitación para el ejercicio de derechos y funciones públicas. Y el tipo penal que le sigue en orden, esto es, el artículo 415, consagratorio de las circunstancias de agravación punitiva, incrementa las penas cuando el prevaricato se consuma en actuación judicial que se adelanta por delitos de genocidio, tortura, desplazamiento for- 
zado, desaparición forzada, secuestro extorsivo, extorsión, concierto para delinquir, etcétera.

En atención a ello, el delito quedó consumado o perfecto, desde el momento en que los defensores y defensoras de oficio, omitieron pedir, deprecar, o solicitar mostrando un verdadero interés y en debida forma, los daños y perjuicios dentro de sus carpetas contentivas de los incidentes de reparación integral. Huelga resaltar que los defensores y defensoras públicas son contratados por la entidad, precisamente para que defiendan a personas en estado de indefensión, de escasos recursos, es decir, a víctimas del paramilitarismo o de la guerrilla, de modo que dentro del manual de funciones que la defensoría del pueblo le entrega a estos defensores/as para que lo estudien y apliquen en su ejercicio profesional, están dadas, señaladas, detalladas y, especificadas, todas sus funciones, por lo antedicho, le resultaría sumamente fácil al fiscal del caso, adecuar el comportamiento de estos defensores/as públicos al ilícito penal de prevaricato por omisión, pues resultaría sencillo determinar la norma que les asigna la función de defensa de víctimas y que fue omitida por los/las implicados/as.

En su libro sobre los delitos contra la administración pública. Gómez (2004) señala. "La palabra prevaricato significa andar torcido, (varicare) o torcimiento del derecho. La jurisprudencia penal ha dicho que el prevaricato (...) en su esencia, radica en la discordancia entre el derecho que el funcionario conoce, y el que se aplica" (p.421). De otro lado y probatoriamente hablando, para poder de manera correcta realizar un juicio de adecuación típica y eventualmente imputarle a los defensores y defensoras públicas estas conductas punibles de prevaricato por omisión, las cuales han venido cometiendo dentro de las salas de audiencia de justicia y paz, debemos acudir al siguiente pronunciamiento de la Honorable Corte Suprema de Justicia en su sala penal. Resulta que afortunadamente, mediante sentencia número 34852 de junio 27 del año 2012, con ponencia del honorable magistrado Julio Enrique Socha Salamanca, se dijo que para que procediera el juicio de adecuación típica en forma correcta, la sala debía aclarar que, en la conducta realizada por el investigado, pueden hallarse intenciones distintas al dolo, como la superficialidad, el capricho, o el desinterés, y sin que tales circunstancias riñan con la imputación al tipo subjetivo.
Son esas intenciones, "la superficialidad y el desinterés", las cuales se han arraigado en los corazones de estos defensores y defensoras públicas, las que han obstaculizado la prosperidad de plenas e individuales indemnizaciones monetarias en favor de las víctimas, y que además, han derivado en centenares de excluidos de las reparaciones a las que tienen derecho, y es por lo acabado de manifestar que este artículo crítico reflexivo, será puesto a disposición de los medios de comunicación como un documento de denuncia, para que la fiscalía proceda a investigar a los presuntos implicados.

\section{Conclusiones}

Las defensas judiciales que hasta ahora han sido desplegadas por las/los defensoras/es públicos/as adscritos al sistema nacional de defensoría, han sido desastrosas, puesto que, desde un prisma intelectual, estos letrados/as no se han preocupado por estudiar la teoría del daño, así como su prueba y su reparación. Y en consecuencia también se concluye que este déficit en lo cualitativo, tiene repercusiones directas en el aspecto cuantitativo, entendido este último como la consecuencia obligada consistente en las bajísimas indemnizaciones monetarias e individuales. Es por ello que después de que este artículo sea sometido a la consideración de la academia y de la sociedad en general, seguramente cambiará la imagen cualitativa de la política pública que debería desarrollar la defensoría del pueblo, y cambiará toda vez que lo cualitativo depende de la percepción social, cultural y subjetiva que los colombianos se formarán de aquí en más de la defensoría pública y del trabajo que viene desarrollando supuestamente en pro de nuestras víctimas.

Se concluye que, si en once (11) años que lleva operando la defensoría pública en "defensa" de nuestras víctimas participantes en justicia y paz, es decir, desde el año 2005 y hasta la fecha presente, no ha corregido sus debilidades en materia de conocimientos jurídicos, forma de deprecar los daños, y manera de acreditarlos, difícilmente va a dar un viraje en su forma de litigar no sólo dentro del marco de estos incidentes de reparación integral, sino también dentro de la jurisdicción especial para la paz. Se concluye que la intención de indemnizar integralmente a las víctimas, plasmada en los preceptos $8^{\circ}$, y 44 a 49 de la ley 975 del año 2005, respecto del componente dinerario de reparación, no ha sido acogida en sus sentencias por parte del tribunal de justicia 
y paz de Bogotá, pero no debido a la falta de recursos públicos, o a la reticencia de las magistradas/os para conceder cuantiosas indemnizaciones, sino merced a la pésima labor defensorial de la política pública representada en la defensa de víctimas por parte de la defensoría del pueblo.

Se concluye que la alternativa de solución a la problemática de las malas defensas y sus consecuenciales bajas indemnizaciones, debe consistir en sugerir en principio a la defensoría pública, que adopté el sencillo protocolo que elaboré para la estructuración de este artículo y que expongo a continuación.

El protocolo para sustentar probatoriamente los incidentes de reparación integral es el siguiente: sintética y pedagógicamente, ya que no pretendo pontificar sobre el tema, simplemente diré que lo primero que debe ser incorporado en la respectiva carpeta contentiva del incidente de reparación integral, son las pruebas documentales con las que se pretende acreditar el daño emergente, bien sea pasado, o futuro, por ejemplo; si el defensor público o privado desea que le reconozcan el valor de un vehículo que fue hurtado por el grupo armado ilegal, y del que se derivaba el sustento para una familia, y además se quiere acreditar la calidad de empresario del occiso, quien a su vez era el que trabajaba utilizando el automotor para vender mercancías, se deberá incorporar entonces, documentales como las siguientes:

El certificado de matrícula de persona natural expedido por la cámara de comercio, para probar que la víctima directa sí era un comerciante legalmente inscrito; recibos que acrediten que la víctima directa cancelaba sus derechos de matrícula como comerciante, así como los derechos de matrícula de sus establecimientos de comercio; el formulario de matrícula mercantil o renovación de personas naturales; facturas y recibos de compra y venta respecto de los bienes y servicios que comerciaba el obitado; copia del carnet de la DIAN de la víctima directa; copia de la declaración de renta del de cujus, avalada por contador público; copia del contrato de compraventa del vehículo, etcétera, aclarando que este listado es enunciativo más no taxativo.

Además, se debe aportar la liquidación del daño emergente pasado y futuro, con la respectiva indexación de los valores, y con base en la conocida fórmula del IPC final, sobre el IPC inicial, * VH $=$ VA.
Ahora bien, si de lo que se trata es de probar la existencia del lucro cesante en su doble dimensión, deberán allegarse los registros civiles de nacimiento y defunción de la víctima directa, así como los de los familiares que reclaman este rubro del daño, también la tabla de mortalidad de rentistas expedida por la superintendencia financiera de Colombia, y esto debe hacerlo el mismo defensor o defensora y sin la ayuda de peritos, para lo cual deberá citar la sentencia de la honorable corte suprema de justicia fechada el 3 de octubre del año 2003 bajo el expediente \# 7368 y con ponencia del profesor José Fernando Ramírez Gómez, entonces, son los defensores quienes deben aportar la liquidación actualizada por concepto de lucro cesante causado o consolidado, y del no causado o no consolidado, de modo que previa indexación de la cifra de base o base económica se itera, con la fórmula: IPC final / IPC inicial * VH = VA, deberá el defensor público aplicar las siguientes sencillas fórmulas de matemáticas financiera: $\mathrm{Sb}=\mathrm{Ra}(1+\mathrm{i}) \mathrm{n}-1 /$ I y $\mathrm{Sb}=\mathrm{Ra}(1+\mathrm{i}) \mathrm{n}-1 / \mathrm{i}(1+\mathrm{i}) \mathrm{n}$

¡Pero por Dios!, lo que no debe hacerse, ya que denotaría pereza mental y académica, es solicitar a la magistratura de justicia y paz, que se sirva liquidar el lucro cesante y el daño emergente, sin aportar ellos mismos [los defensores/as], esos cálculos actuariales ni los documentos en que estos se asientan que, tal y como quedó probado, es la manera de actuar de estos colegas que se alimentan mensualmente del erario. Así como tampoco, ya que hablaría muy mal de la preparación jurídica del abogado que así proceda, se puede solicitar al juez colegiado, que dé por probado el parentesco a base de declaraciones extrajuicio, ya que, al respecto, resulta pertinente recordar lo que frente a este tema de la prueba del parentesco y el registro civil, ha dicho el honorable consejo de estado colombiano. Recordemos que el consejo de estado ha dicho que los asuntos atinentes a las pruebas del estado civil, se regulan por el decreto ley 1260 de 1970, el cual en su artículo 105, determina que los hechos y actos relacionados con el estado civil de las personas, ocurridos con posterioridad a la vigencia de la ley 92 de 1938 , se prueban con copia de la correspondiente partida o folio, o con certificados expedidos con base en los mismos.

Pero sigamos, miremos ahora cómo se acreditan los daños de orden inmaterial, tales como los perjuicios morales o el daño a la vida de relación, etcétera. Es prudente señalar que se puede solicitar a la magistratura, que aplique presunciones, pero es que las mismas, deben ir aparejadas de las 
citas de las jurisprudencias que las han establecido, verbigracia, respecto de los perjuicios morales, se podrían invocar entre otras, las siguientes sentencias: Consejo de Estado, sección tercera, del 17/7/1992, expediente 6750, con ponencia del consejero Daniel Suarez Hernández; sentencia del 16/7/1998, de la sección $3^{\mathrm{a}}$, expediente No 109016; sentencia del 8/2/1992, magistrado Daniel Suarez Hernández; C.S. de J, cas, civil, Sentencia de mayo 11 de 1976; CSJ. Cas. Civil, mayo 23 de 1990; C de E, sección $3^{\mathrm{a}}$, 5 de febrero de 1988, expediente No 3009; fallo de 21 de febrero de 1997 del mismo ponente. Expediente No 10083; sentencia del 22 de agosto de 1996, expediente No 10220; sentencia fechada el 5 de mayo de 1999. Expediente No 4978.

Y para los perjuicios fisiológicos o daño a la vida de relación, estos sí deben acreditarse con declaración de testigos, quienes deberán ser llevados por los defensores públicos a las salas de las audiencias, ya que respecto de esta clase de perjuicios, el consejo de estado dijo que se deben probar con este específico medio de prueba testimonial, pues no basta con la sumaria, ni mucho menos con presunciones pretorianas para tenerlos por probados, salvo claro está, las hipótesis de reparación directa por privación injusta de la libertad, en donde también se presumen los daños a la vida de relación o perjuicios fisiológicos de la víctima directa, pero lo que no debe hacerse, y que es lo que vienen haciendo los defensores públicos/as, es solicitar que se den por probados con base en presunciones que, ya sabemos, no proceden. Y si de deprecar el reconocimiento del daño punitivo o punitive damage se trata, pues los defensores de oficio, en primer lugar, deben citar los referentes de la tradición jurídica del common law, así por ejemplo, en el derecho norteamericano, encontramos el caso Reynolds $v s$. Pegler, SD NY, 1954; o el caso Toomey vs. Farley, SD NY, 1956; o el caso Livesey vs. Stock, SD NY, 1929; o el caso Seaman vs. Dexter, SD NY, 1921; o el Pelton vs. General Motors, SD NY, 1932: 225. Y en el derecho inglés, el caso Cassel y Co. Ltda vs. Broome, AC, 1927; o el caso Grimshaw vs. Ford Motors Company, AC, 1981.

En segundo lugar, deben citar los precedentes jurisprudenciales de nuestra región, es decir, se deben invocar casos fallados por los tribunales de la región andina, esto es, procesos resueltos bajo la tradición jurídica continental que nos rige o civil law, así por ejemplo, podrían citar un paradigmático caso que ya fue objeto de reconocimiento en los países del cono sur, y que fue el acaecido en la argentina en el año 2010, en donde la justicia de ese país, sancionó civilmente a una empresa de telecomunicaciones, telefónica móviles Argentina, por el punitive damage del common law. Este protocolo también exhorta a los defensores y defensoras públicas, a solicitar a la magistratura el reconocimiento del medio de prueba indiciaria o indirecta, supremamente importante cuando de acreditar daños y perjuicios de naturaleza patrimonial y extrapatrimonial se trata, jindicios unidos jamás serán vencidos!, dice la máxima procesal.

No olvidemos que este medio de prueba indirecto, se encuentra conformado por una premisa mayor o regla de la experiencia que enseña, así como por una premisa menor o hecho conocido, hecho base, hecho indicio o indicante, que debe estar probado, verbigracia, el parentesco, de la premisa menor también forma parte la inferencia lógica que ata el hecho indicante con las reglas de la experiencia y, una conclusión, o hecho desconocido o hecho indicado, v., gr. la existencia de los perjuicios inmateriales, o de una ayuda económica, etcétera.

Para finalizar, en lo que toca con las presunciones, los defensores públicos deben abandonar la perniciosa costumbre de estar buscando estándares de cuantificación del daño, es decir, de estarle solicitando a los magistrados/as el reenvío a dichos estándares, para así suplir su negligencia y denotada pereza en materia de falta de prueba del perjuicio. Y del mismo modo, los magistrados/as de justicia y paz, quienes han sido bastante pasivos y permisivos en el debate probatorio, deben hacer mayor uso de las facultades que otorga el código general del proceso en punto del decreto de pruebas de oficio, pero no solamente limitándose a decretar de oficio exámenes de ADN, sino también decretando ex officio otras probanzas que permitan por ejemplo, vincular al Estado como agente directo del daño, ya que es preferible rastrear los hechos y cazar su prueba, que andar declarando presunciones que, junto con las ficciones, no son más que faunos probatorios. Se concluye que las víctimas de la guerrilla, las cuales ingresarán al sistema de justicia de excepción que se está creando en la Habana, tampoco van a ser bien asistidas judicialmente por parte de la defensoría pública, toda vez que no se vislumbra razón alguna como para confiar en que los defensores y defensoras públicas, van a adoptar con estas otras víctimas, una actitud encaminada a desplegar defensas responsables para ellas, defensas basadas en juiciosos estudios previos sobre la teoría del daño y su prueba, defensas determinadas por diligentes manejos probatorios. 


\section{Referencias bibliográficas:}

Amnistía internacional. (2012). Bosnia y Herzegovina: La República Srpska debe conceder reparaciones para las violaciones sexuales perpetradas durante la guerra. Recuperado de https://www. amnesty. org/es/press-releases/2012/10/bosnia-herzegovina-srpska-reparaciones

Anónimo. (2015). Las deudas de justicia y paz con las víctimas. Verdadabierta.com. Recuperado de http://www.verdadabierta.com/justicia-y-paz/reparaciones-a-victimas/5702-las-_deudas-de-justiciay-paz-con-las-victimas

Anónimo. (2011). Un mundo en deuda con las víctimas. Semana.com. Recuperado de http://www.semana.com/nacion/articulo/un-mundo-deuda-victimas/240498-3

Bustamante, J. (1983). Teoría general de la responsabilidad civil. Buenos Aires: Abeledo-Perrot.

Calabresi, G. (2006). El coste de los accidentes. Análisis económico y jurídico de la responsabilidad civil. Barcelona: Ariel.

Daray, H. (2000). Daño psicológico. Buenos Aires: Astrea.

De Cupis, A. (1970). Teoria general de la responsabilidad civil. Barcelona: Bosch

Escobar, R. (1989). Responsabilidad contractual de la administración pública. Bogotá: Temis.

Fernández, C. (1999). Daño al proyecto de vida. Revista de responsabilidad civil de Estado del Instituto Antioqueño de responsabilidad civil y del Estado, 6, 64-65

Gallón, G. (2014). Ocho años de justicia y paz: un balance con más sombras que luces.

Razónpública.com. Recuperado de http://www.razonpublica.com/index. php/conflicto-drogas-y-paz-temas-30/7446-ocho-a\%C3\%B1osde- $\%$ E2\% $80 \% 9$ Cjusticia-y-paz $\%$ E2\%80\%9D-un-balance-conm\%C3\%A1s-sombras-que-luces.html

Gómez, A. (2004). Delitos contra la administración pública. Bogotá: Universidad externado de Colombia.

Henao, J. C. (1998). El daño. Bogotá: Universidad Externado de Colombia
Henao J. C. (1998). El daño. Análisis comparativo de la responsabilidad extracontractual del Estado en Derecho colombiano y francés. Bogotá: Universidad Externado de Colombia.

Hinestrosa, F. (1967). Derecho de obligaciones. Bogotá: Universidad Externado de Colombia.

Martínez, R. (2006). Diccionario jurídico general. México: IURE.

Martínez, G. (2003). Responsabilidad civil extracontractual. Bogotá: Temis.

Mazeaud, H. (1977). Tratado teórico práctico de la responsabilidad civil delictual y Contractual. Buenos Aires: Ejea.

Mcausalnd, M. C. (2011). Tipología del daño inmaterial. Bogotá: Universidad Externado de Colombia.

Montañés, X.K. (2014). A ocho años de la ley de justicia y paz, ¿cuál es el balance? Vanguardia.com. Recuperado de http://www.vanguardia.com/actualidad/politica/259797-a-ocho-anos-de-la-leyde-justicia-y-paz-cual-es-el-balance

Organización de Naciones Unidas. (2015). Informe S/2015/203. Recuperado de http://www.un.org/sexualviolenceinconflict/es/ paises/bosnia-y-herzegovina

Parra Guzmán, M. F. (2010). Responsabilidad civil. Bogotá: Doctrina $y$ Ley.

Rozo, P. E. (2002). El daño biológico. Bogotá: Universidad Externado de Colombia.

Rubio, S. (2016). Reparaciones y construcción de paz en Colombia un panorama para el postacuerdo [mensaje en un blog de la fundación para el debido proceso]. Recuperado de https://dplfblog. com/2016/05/06/reparaciones-y-construccion-de-paz-en-colombia-un-panorama-para-el-post-acuerdo

Tamayo Jaramillo, J. (1986). De la responsabilidad civil. Bogotá: Temis.

Tomuschat, C. (2005). Cuadernos del conflicto: justicia, verdad y reparación en medio del conflicto. Fundación ideas para la paz, revista Semana. Recuperado de http://www.acnur.org/t3/uploads/ media/COI 1610.pdf?view=1 
Velásquez, O. (2013). Responsabilidad civil extracontractual. Bogotá: Temis.

Yzquierdo, M. (2001). Sistema de responsabilidad civil contractual y extracontractual. Madrid: Dykinson.

Zanoni, E. (2005). El daño. Buenos Aires: Astrea.

\section{Notas:}

Se aclara que esta línea jurisprudencial emanó de la sección tercera del consejo de estado mediante sentencia del 24 de septiembre del año 1993, con ponencia del consejero Suárez Hernández, y dentro del expediente No 8298 .

Se aclara que esta línea jurisprudencial, no emanó de un tribunal sino directamente de la Corte Suprema de Justicia en su sala de casación civil.

Se aclara que esta línea jurisprudencial emanó de la Corte Suprema de Justicia en su sala de casación civil.

Se aclara que estas líneas jurisprudenciales, emanaron de la sección tercera del Consejo de Estado el 6 de febrero del año 1992, bajo el expediente \# 6030; y el 11 de diciembre del mismo año, bajo el radicado \# 7403 .

Se aclara que la primera providencia que marcó línea en tal sentido, fue producida por la CSJ, Cas. Civil, en octubre 3 del año 2003, bajo el expediente No 7368, con ponencia del magistrado José Fernando Ramírez Gómez. 